\title{
O caráter adaptativo da governança das águas em sistemas hídricos locais
}

\author{
The adaptive aspect of water governance in local water \\ resources systems
}

Maycon Breno Macena da Silva ${ }^{1}$ (D), Márcia Maria Rios Ribeiro ${ }^{1}$ (C)

${ }^{1}$ Universidade Federal de Campina Grande - UFCG, Campina Grande, PB, Brasil. E-mails: sbrenomacena@gmail.com, mm-ribeiro@uol.com.br

Como citar: Silva, M. B. M., \& Ribeiro, M. M. R. (2021). 0 caráter adaptativo da governança das águas em sistemas hídricos locais. Revista de Gestão de Água da América Latina, 18, e22. https://doi.org/10.21168/rega.v18e22

\begin{abstract}
RESUMO: Os recursos hídricos estão sujeitos a diferentes tipos de perturbações que podem causar impactos consideráveis na dimensão social e ecológica dos sistemas hídricos. Diante disso, surge a necessidade de construir uma governança de águas adaptativa, possibilitando gerir os efeitos causados por estresses. Como os sistemas não se encontram isolados e as problemáticas são distintas para os diferentes níveis de planejamento, é importante que qualquer análise consistente da governança leve em consideração uma perspectiva multinível. Sendo assim, foi analisado em quatro níveis distintos de uma escala espacial o caráter adaptativo da governança de águas nas dimensões legal e institucional. A análise de conteúdo foi utilizada para encontrar nos documentos a presença de indicadores que favoreçam o desenvolvimento de uma governança adaptativa. Nos diferentes níveis, foram encontrados muitos aspectos, como policentricidade e integração, que sugerem capacidade para adaptação. A governança analisada ao nível de sistema hídrico local, no Reservatório Epitácio Pessoa, mostrou-se potencializadora da adaptação devido, sobretudo, ao processo de alocação negociada de água em curso. Contudo, faz-se necessário direcionar atenção também à implementação das diretrizes analisadas, para que assim se perceba os impactos de uma governança de águas preparada para lidar com as incertezas e complexidade.
\end{abstract}

Palavras-chave: Governança Adaptativa; Sistemas Hídricos Locais; Complexidade; Incertezas; Análise Multinível.

\begin{abstract}
Water resources are subject to different types of disturbances that might have considerable impacts on the social and ecological dimensions of systems. Therefore, there is a need to build adaptive water governance, making it possible to manage the effects caused by stresses. As systems are not isolated and issues are different for different levels of planning, a consistent analysis of governance must consider a multilevel perspective. Thus, the adaptive character of water governance in the legal and institutional dimensions was analyzed at four distinct levels of a spatial scale. Content analysis was used to find in the documents the presence of indicators that favor the development of adaptive governance. At different levels, many aspects were found, such as polycentricity and integration, that suggest a capacity for adaptation. The governance analyzed at the level of the local water system in the Epitácio Pessoa Reservoir proved to enhance adaptation due, above all, to the process of negotiable water allocation in progress. However, it is also necessary to drive attention to the implementation of the analyzed rules so that the impacts of water governance prepared to deal with uncertainties and complexity can be perceived.
\end{abstract}

Keywords: Adaptive Governance; Local Water Systems; Complexity; Uncertainties; Multilevel Analysis.

\section{INTRODUÇÃO}

As incertezas sociais ou ecológicas associadas aos recursos hídricos adicionam considerável complexidade aos sistemas hídricos. Isto é confirmado em muitas das teorias que orientam mudanças e observam esses sistemas, como a hidrocomplexidade (Kumar, 2015), a sociohidrologia (Sivapalan et al., 2012) e a teoria dos sistemas socioecológicos (Ostrom, 2007; McGinnis \& Ostrom, 2014). Além disso, é atualmente aceito que as problemáticas envolvendo os recursos hídricos são dadas, sobretudo, por crises de governança em vários níveis de planejamento (Pahl-Wostl, 2017), visto que, por muito tempo, tanto os sistemas de governança como as políticas de recursos hídricos foram

Recebido: Junho 28, 2021. Revisado: Setembro 20, 2021. Aceito: Outubro 18, 2021. 
orientados por soluções simplistas, como as privatizações e a descentralização sem coordenação entre os diversos centros de poder (Pahl-Wostl, 2019).

Diante disso, se torna cada vez mais necessário direcionar atenção à governança das águas e aos caminhos para implementá-la de forma satisfatória (Pahl-Wostl, 2015). A governança lida com o conjunto de normas técnicas e jurídicas, ações, instituições (formais ou não) e processos administrativos que levam os atores envolvidos a se articular, tomar decisões acerca da gestão e implementá-las (Organization for Economic Co-operation and Development, 2015; Chaffin \& Gunderson, 2016). Portanto, a gestão e a governança não são sinônimos. A gestão é entendida como a técnica que abrange o planejamento em si e a mediação, sendo então, a operacionalização da governança (Armitage et al., 2012; Observatório das Águas, 2019a). A gestão depende da governança atuante em vários níveis, visto que muitas vezes os limites hidrológicos e administrativos de uma região não são coincidentes (Bezerra, 2019). Para Knieper \& Pahl-Wostl (2016), a governança combinada a outros fatores sociais gera boas práticas de gestão dos recursos hídricos, mas o conhecimento acerca da governança da água ainda é limitado, o que explica este ser um campo do conhecimento acadêmico em rápido crescimento (Pahl-Wostl, 2017).

Quando a governança assume um caráter adaptativo possibilita que os sistemas respondam melhor às falhas, evitem a degradação e minimizem o ambiente propício aos conflitos pela alocação de recursos (Chaffin \& Gunderson, 2016; DeCaro et al., 2017). Segundo Shivakumar (2005), a governança pode ser uma facilitadora à adaptação, ajudando os sistemas a passar por períodos de transições. Nesse sentido, o conceito da Governança Adaptativa (GA) surge como uma abordagem emergente e potencializadora para que os sistemas de recursos hídricos consigam lidar com as incertezas e complexidades na era do antropoceno (Ribeiro \& Johnsson, 2018; Plummer \& Baird, 2021). Para Chaffin et al. (2014), a GA consiste em um sistema de governança ambiental composto por uma gama de interações entre atores, redes, organizações e instituições em busca de um estado satisfatório para o local ao qual se aplica diante das incertezas e complexidades associadas às rápidas mudanças. Estas duas características (incerteza e complexidade) envolvem tanto aspectos ecossistêmicos como institucionais (Scholz \& Stiftel, 2005; Pahl-Wostl et al., 2012; Hurlbert \& Gupta, 2016).

O Observatório das Águas (OGA) no Brasil entende que o firmamento de uma governança sólida perpassa cinco dimensões que estão atreladas entre si, sendo elas: a construção de aspectos legais e institucionais; capacidade estatal; presença de instrumentos de gestão; relações estado-sociedade; e relações intergovernamentais (Observatório das Águas, 2019a).

Constituindo a primeira dimensão citada pelo Observatório das Águas (2019a), os dispositivos jurídicos e normativos funcionam como um mecanismo de organização. Eles são imprescindíveis para orientar a estrutura, os limites, as regras e os processos que estarão vinculados ao nível em que a governança deve ser aplicada e são cruciais para análise das barreiras à adaptação (Ruhl, 2011; Cosens et al., 2017). Atuam em toda estrutura da governança, afetando todas as escalas, os atores e instituições, sejam elas formais ou informais. Os dispositivos legais surgem como uma maneira de facilitar a adaptação nos sistemas socioecológicos por meio da auto-organização, coordenação e colaboração entre escalas (DeCaro et al., 2017). Craig et al. (2017) mostram que muitos autores têm orientado para a adequação da legislação ambiental para alcançar sistemas mais resilientes e com uma gestão adaptativa capaz de operacionalizar adequadamente a GA.

Cosens et al. (2017) apresentam um conjunto de características que ao serem identificadas nos dispositivos jurídicos podem contribuir para a presença e fortalecimento de uma GA. Essas características se apoiam em três aspectos: estrutura, que corresponde ao desenho institucional; capacidade, relacionada aos recursos e autoridade para responder às mudanças; e processo, que é essencial para a garantia da implementação das prerrogativas estabelecidas.

O papel dos dispositivos jurídicos e normativos na GA já foi investigado em nível nacional (Bettini et al., 2015; Novellie et al., 2016; Craig et al., 2017) e de bacia hidrográfica (Cosens, 2015; Cosens \& Gunderson, 2021). Mas para Daniell e Barreteau (2014) a governança precisa ser pensada e analisada em vários níveis e escalas. Escalas caracterizam, por exemplo, as dimensões espaciais, temporais, legislativas e institucionais, enquanto os níveis são os conjuntos de classes que fracionam uma escala (Cash et al., 2006; Daniell \& Barreteau, 2014). Logo o mais sensato é que a jurisdição e normativas também sejam analisadas dessa forma. Principalmente se a governança estiver baseada num arcabouço jurídico que preze pela descentralização, como a Política Nacional de Recursos Hídricos (PNRH) brasileira (Brasil, 1997; Ribeiro, 2017).

Cada nação apresenta uma composição jurídica (também chamada de legal) que orienta como os recursos naturais devem ser geridos. Nesse sentido, para Granziera (2003, p. 34) o direito de águas brasileiro corresponde ao "conjunto de princípios e normas jurídicas que disciplinam o domínio, uso, 
as competências e o gerenciamento das águas visando ao planejamento dos usos e à preservação, assim como a defesa de seus efeitos danosos, provocados ou não pela ação humana". Na confederação brasileira (formada pela União, os Estados Federados e os Municípios) cabe à União e aos Estados legislar acerca da gestão das águas e aos municípios responsabilidades de interesse local, como o abastecimento de água que compõe o saneamento básico (Agência Nacional de Águas e Saneamento Básico, 2020a). Além disso, a bacia hidrográfica é a unidade territorial de gestão na PNRH (Brasil, 1997), então dessa forma, o planejamento dos recursos hídricos no Brasil se faz em níveis distintos dentro de uma escala espacial: em nível nacional, estadual, de bacia hidrográfica e no nível de sistema hídrico local. Esse planejamento ocorre por meio de leis (elaboradas pela União e Estados), planos de recursos hídricos (para União, Estados e bacias) e resoluções e atos normativos (para todos os níveis, sendo subordinados às leis vigentes).

Nesta pesquisa chama-se de sistema hídrico local, o arranjo composto por um reservatório, os atores envolvidos na sua exploração e gestão, e as normas que regulamentam os usos. 0 planejamento nesse nível passou a ser mais visibilizado nacionalmente com a criação da Coordenação de Marcos Regulatórios e Alocação de Água (COMAR), grupo de profissionais da Agência Nacional de Águas e Saneamento Básico (ANA) subordinados à Superintendência de Regulação (Agência Nacional de Águas e Saneamento Básico, 2017). A COMAR tem implementado uma metodologia de alocação negociada de água em reservatórios do semiárido para melhorar a gestão por meio da participação e descentralização, o que consiste em uma de suas atribuições (Agência Nacional de Águas e Saneamento Básico, 2017, 2021).

O nível de aplicação dos dispositivos jurídicos e normativos também está totalmente atrelado à dominialidade dos corpos hídricos. A Constituição Federal (Brasil, 1988) define que os lagos, rios ou correntes de água que banhem mais de um estado federado ou se estendam para outros países serão de domínio da União, enquanto as águas superficiais ou subterrâneas são de domínio estadual, as primeiras quando estiverem contidas em um único estado e as segundas em qualquer situação. Já os lagos e reservatórios serão de domínio da União sempre que construídos com recursos federais (Agência Nacional de Águas e Saneamento Básico, 2020a) e mesmo que estejam barrando um rio de domínio estadual. Essas distinções adicionam mais complexidade à governança das águas.

Mesmo que exista diferenciação nos níveis de planejamento e, consequentemente, nos dispositivos jurídicos e normativos, eles precisam estar integrados para que não haja conflito entre as prerrogativas ao serem aplicadas (Pedrosa, 2020). Assis et al. (2020) exemplificam, de forma indireta, como essa integração é realizada numa bacia hidrográfica interestadual de grande dimensão (a do rio São Francisco) e o quão complexo pode ser.

Para avaliar aspectos da GA em cenário de complexidade exige-se um olhar multinível, com vários pontos de análise, abarcando inclusive os sistemas hídricos locais, que surgem como um nível a ser observado ainda mais micro que o de bacia ou sub-bacia. Tal ação se justifica ao perceber que mesmo bacias que possuem plano de recursos hídricos e um comitê em funcionamento, podem apresentar reservatórios em situação de crise e conflito. Isto ocorre sobretudo se o plano não considerar em detalhes as questões conflitantes que envolvem os reservatórios e se o comitê não atuar adequadamente para resolvê-las. 0 estado do Ceará tem um modelo de planejamento e gestão que considera a governança em nível de reservatório, sobretudo por incluir na composição institucional as Comissões Gestoras de Açudes (CGA) como componentes dos comitês de bacia (Rodrigues, 2014). No caso do Reservatório Epitácio Pessoa localizado na bacia do rio Paraíba, foco de estudo neste trabalho, se estivesse sendo bem acompanhado como sistema hídrico local, maior teria sido a possibilidade de uma governança adequada. Assim como Cosens et al. (2014b) sugerem que os problemas de governança costumam ser distintos entre o nível de bacia hidrográfica e os sistemas mais amplos, esta pesquisa sugere que esses problemas também podem ser diferentes quando comparam-se situações em nível de bacia e em uma escala local (de governança no nível de reservatório).

Reconhecendo a necessidade de incentivar no Brasil o diálogo sobre adaptação dos sistemas de recursos hídricos diante das incertezas e complexidades socioambientais, esta pesquisa busca identificar nas dimensões legal e institucional da governança de águas características associadas à GA, observando as particularidades em escala espacial por meio de uma análise multinível. Além disso, considerando um sistema hídrico local como ponto focal de análise pretende-se mostrar que estes sistemas compõem um importante nível de planejamento, principalmente, quando integrados satisfatoriamente a outros níveis. 


\section{METODOLOGIA}

\section{Áreas de estudo}

O trabalho utilizou o conceito de Cash et al. (2006) de escala e níveis para analisar os dispositivos jurídicos e normativos. A escala escolhida foi a espacial. O ponto focal de análise constitui-se do sistema hídrico local composto pelo Reservatório Epitácio Pessoa (REP), mas como a governança desse sistema depende dos dispositivos e instituições de outras dimensões, foi realizada uma avaliação multinível: nível nacional (Brasil), estadual (Paraíba), bacia hidrográfica (bacia hidrográfica do rio Paraíba) e sistema hídrico local (composto pelo REP) (Figura 1). Dessa forma, mesmo que o ponto de partida seja o REP, a análise permitirá avaliar outros níveis aninhados a este.

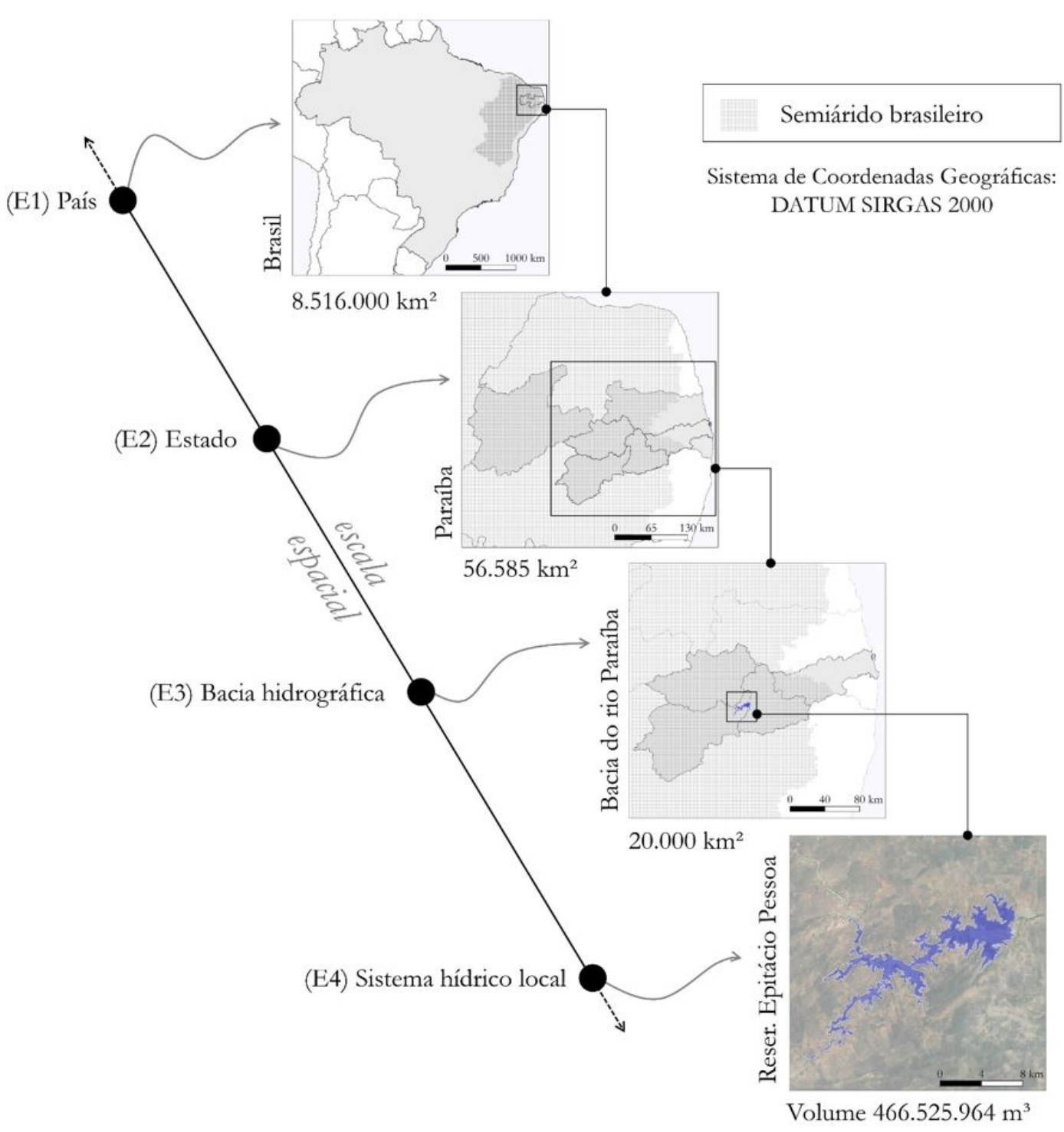

Figura 1 - Níveis utilizados para análise do caráter adaptativo da governança das águas.

O Brasil possui uma PNRH considerada moderna, descentralizada e de caráter participativo (Veiga \& Magrini, 2013; Silva et al., 2017; Susana Neto et al., 2017). A Lei Federal 9.433 de 1997, criou a PNRH e o Sistema Nacional de Gerenciamento de Recursos Hídricos (SINGREH), que corresponde às instituições que possibilitam deliberar, consultar, planejar e gerenciar os recursos hídricos em seus múltiplos níveis. Além disso, a lei traz em seu conteúdo cinco instrumentos de gestão para permitir que seus princípios sejam implementados: os planos de recursos hídricos, o enquadramento dos 
corpos d'água em classes, a outorga para o direito de uso da água, a cobrança pelo uso da água bruta e os sistemas de informação sobre recursos hídricos.

A Política Estadual de Recursos Hídricos (PERH) na Paraíba foi criada em 1996 pela Lei Estadual 6.308. Onze anos depois foi modificada para se adequar à PNRH, devido à necessidade de haver integração entre as prerrogativas em seus distintos níveis para minimizar os conflitos no momento da aplicação.

A Bacia Hidrográfica do Rio Paraíba (BHRP) é a segunda maior do Estado, com pouco mais de $20.000 \mathrm{~km}^{2}$ (38\% do território estadual). Mais da metade da população do Estado da Paraíba reside nos municípios que estão inseridos na bacia, inclusive os dois mais populosos (a capital João Pessoa e Campina Grande) são importantes polos econômicos, educacionais e tecnológicos (Ribeiro et al., 2012). O rio que compõe a bacia está contido totalmente no estado, então o domínio é estadual. 0 Comitê de Bacia Hidrográfica da Bacia do Rio Paraíba (CBH-PB) foi criado em 2007 e conta com representantes dos usuários de água, do poder público e da sociedade civil, sendo, portanto, uma entidade importante para que a governança das águas seja participativa.

O Reservatório Epitácio Pessoa (REP) é o segundo maior do estado da Paraíba e está localizado na porção semiárida da BHRP. Foi projetado e construído entre 1953 e 1956 pelo Departamento Nacional de Obras Contra as Secas (DNOCS). Dessa forma, o domínio dos recursos desse corpo hídrico é da União, sendo a ANA a responsável pela gestão da água armazenada. O REP é responsável por abastecer 18 municípios, que juntos somam uma população de cerca de 640 mil pessoas (Instituto Brasileiro de Geografia e Estatística, 2018). Além disso, é explorado para fins de irrigação e pesca (Agência Nacional de Águas e Saneamento Básico, 2020b). Sua bacia de drenagem é muito impactada por ações humanas, como o desmatamento (Silva et al., 2017), que somado à má gestão da água (Rêgo et al., 2017) e aos fatores climáticos (Silva et al., 2021), foram propulsores para as duas grandes crises hídricas que o reservatório vivenciou nos últimos 20 anos. A segunda sendo tão severa que ameaçou colapsar o serviço de abastecimento quando o reservatório alcançou pouco mais de 3\% do seu volume total (Rêgo et al., 2017).

\section{Identificação do caráter adaptativo na governança}

0 método executado é apresentado na Figura 2. A abordagem consiste em aplicar a análise de conteúdo fundamentada por Bardin (2016), que por meio de um conjunto de etapas se propõe a extrair, de quaisquer recursos de linguagem, sentidos manifestos ou latentes. Sendo latentes aqueles que aparecem de forma implícita no conteúdo analisado, e os manifestos, aqueles que são mais diretos no que é dito no texto. Neste trabalho os objetos de análise foram documentos e não mensagens na forma de comunicação, como normalmente são usadas na análise de conteúdo. Mas isto não é necessariamente um impeditivo, visto que a finalidade é sempre a mesma (Bardin, 2016) e que uma mensagem também pode ser documental (Franco, 2008).

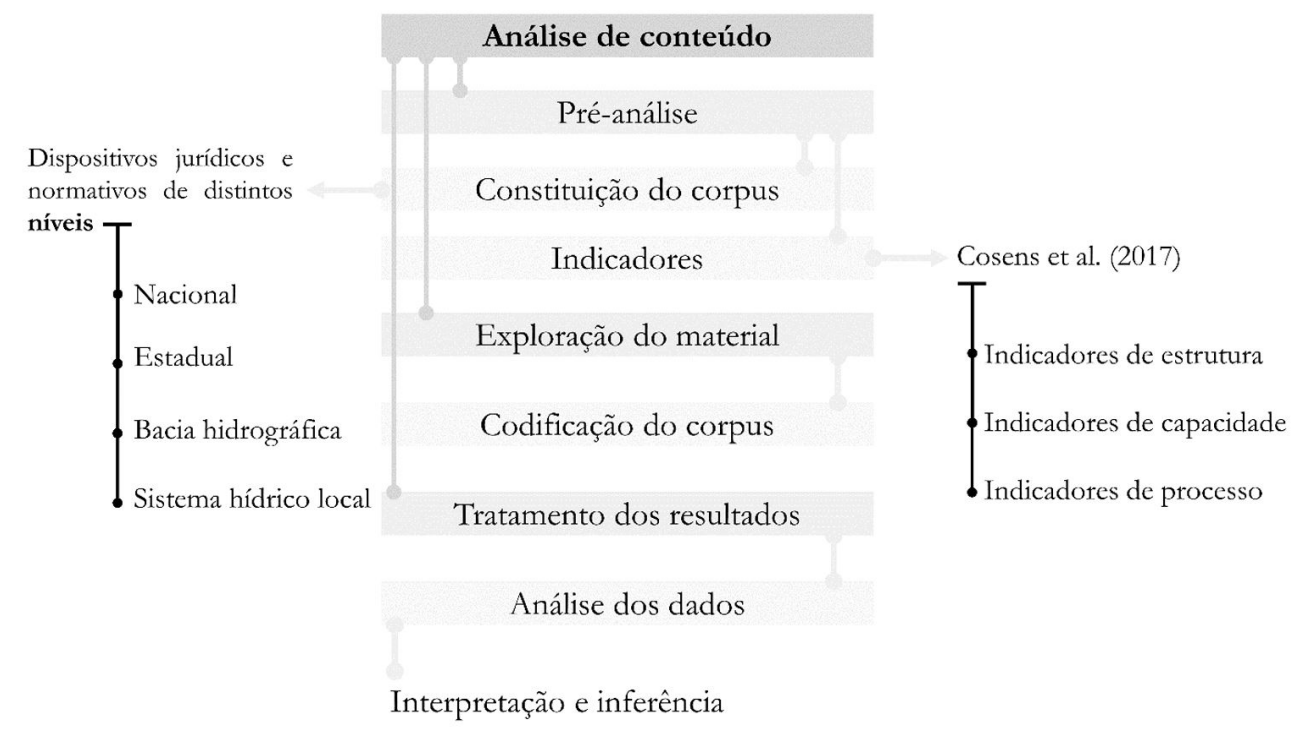

Figura 2 - Método aplicado para análise da dimensão legal e institucional da governança de águas. 
O corpus, grupo de textos selecionados, para análise deste trabalho foi construído por um conjunto de documentos jurídicos ou normativos que tem a possibilidade de adicionar características da GA na forma que os recursos hídricos serão geridos (Quadro 1). Foram escolhidos documentos mais gerais e consolidados, como a Lei Federal 9.433, e dispositivos normativos e acordos mais recentes, como os que estão relacionados ao processo de alocação de água do REP. Foi critério para escolha dos dispositivos o que considerou-se ser documentos de impacto para estruturar a governança, por se tratar de políticas de recursos hídricos (nacional e estadual), diretrizes para os instrumentos de gestão, diretrizes para a composição institucional e metodologia para acordos participativos. Também foi critério de escolha ter algum impacto direto ou indireto no sistema hídrico local escolhido, sendo este, portanto, o ponto focal da análise e utilizado como ponto de partida para o levantamento do material. Ao todo constitui o corpus 15 dispositivos com significância para a governança das águas.

Quadro 1 - Dispositivos analisados para investigar a governança das águas considerando o sistema hídrico do REP.

\begin{tabular}{|c|c|c|}
\hline Nível & Dispositivo & Descrição \\
\hline \multirow{6}{*}{ 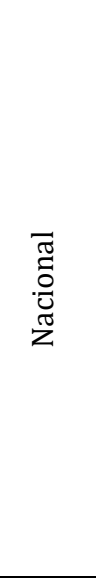 } & Lei Federal nº 9.433 de 1997 & $\begin{array}{l}\text { Institui a Política Nacional de Recursos Hídricos, cria o } \\
\text { Sistema Nacional de Gerenciamento de Recursos Hídricos } \\
\text { - SINGREH }\end{array}$ \\
\hline & Resolução CNRH no 13 de 2000 & $\begin{array}{l}\text { Estabelece critérios gerais para o Sistema Nacional de } \\
\text { Informações sobre Recursos Hídricos }\end{array}$ \\
\hline & Resolução CNRH nº 16 de 2001 & $\begin{array}{l}\text { Estabelece critérios gerais para a outorga de direito de } \\
\text { uso de recursos hídricos }\end{array}$ \\
\hline & Resolução CNRH nº 21 de 2005 & $\begin{array}{l}\text { Estabelece critérios gerais para a cobrança pelo uso dos } \\
\text { recursos hídricos }\end{array}$ \\
\hline & Resolução CNRH nº 91 de 2008 & \begin{tabular}{|lllll} 
Dispõe sobre procedimentos & gerais para & o \\
enquadramento dos corpos de água superficiais & e \\
subterrâneos
\end{tabular} \\
\hline & Resolução CNRH nº 145 de 2012 & $\begin{array}{l}\text { Estabelece diretrizes para a elaboração de Planos de } \\
\text { Recursos Hídricos de Bacias Hidrográficas e dá outras } \\
\text { providencias }\end{array}$ \\
\hline \multirow{2}{*}{ 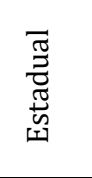 } & Lei Estadual nº 6.308 de 1996 & $\begin{array}{l}\text { Institui a Política Estadual de Recursos Hídricos, suas } \\
\text { diretrizes e dá outras providências }\end{array}$ \\
\hline & Lei Estadual no 7.779 de 2005 & $\begin{array}{l}\text { Cria a Agência Executiva de Gestão das Águas do Estado } \\
\text { da Paraíba - AESA }\end{array}$ \\
\hline \multirow{4}{*}{ 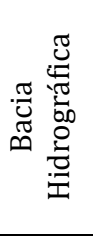 } & Decreto nº 27.560 de 2006 & $\begin{array}{l}\text { Institui o Comitê da Bacia Hidrográfica do Rio Paraíba e } \\
\text { dá outras providências }\end{array}$ \\
\hline & Resolução CERH no 01 de 2003 & $\begin{array}{l}\text { Estabelece diretrizes para a formação, instalação e } \\
\text { funcionamento de Comitês de Bacias }\end{array}$ \\
\hline & Regimento Interno do CBH-PB & \begin{tabular}{|c|}
- \\
\end{tabular} \\
\hline & Deliberações do CBH-PB de 2008 até 2019 & - \\
\hline \multirow{4}{*}{ 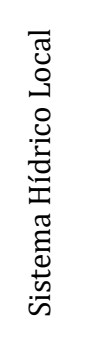 } & Resolução ANA nº 78 de 2019 & $\begin{array}{l}\text { Regulamenta a adoção do Termo de Alocação de Água } \\
\text { para sistemas hídricos com corpos de água de domínio da } \\
\text { União }\end{array}$ \\
\hline & $\begin{array}{l}\text { Nota Técnica } \\
\text { no } 10 / 2015 / C O M A R / S R E\end{array}$ & Metodologia para Alocação de Água em Açudes Isolados \\
\hline & $\begin{array}{l}\text { Termo de Alocação de Água (TAA) 2019- } \\
2020\end{array}$ & - \\
\hline & $\begin{array}{l}\text { Termo de Alocação de Água (TAA) 2020- } \\
2021\end{array}$ & - \\
\hline
\end{tabular}

Os indicadores utilizados foram as características de dispositivos jurídicos levantadas por Cosens et al. (2017) que podem conferir à governança das águas um caráter adaptativo (Quadro 2). Essas características foram consideradas neste trabalho por terem sido investigadas e utilizadas como arcabouço por um período de tempo considerável (desde 2014) pelo grupo de pesquisa que as definiram e validaram com a aplicação na análise da governança de diferentes bacias hidrográficas (Cosens et al., 2014a; Cosens, 2015). 
Quadro 2 - Diretrizes para investigação do papel da lei na governança adaptativa.

\begin{tabular}{|c|c|c|}
\hline $\begin{array}{l}\text { Aspectos da } \\
\text { governança } \\
\text { regidos por lei }\end{array}$ & Componente do aspecto & $\begin{array}{l}\text { Diretrizes descritas para avaliação do } \\
\text { componente da estrutura }\end{array}$ \\
\hline \multirow{7}{*}{ Estrutura } & \multirow{5}{*}{ Policentricidade } & Vários centros de autoridade. \\
\hline & & $\begin{array}{l}\text { - Redundância: funções comuns de gerenciamento } \\
\text { e tomada de decisão em várias escalas. A } \\
\text { redundância aumenta a probabilidade de que as } \\
\text { decisões possam ser tomadas e implementadas na } \\
\text { escala de um problema específico. }\end{array}$ \\
\hline & & $\begin{array}{l}\text { - Aninhamento: representação de órgãos de } \\
\text { decisão e assessoria de níveis inferiores em } \\
\text { entidades de nível superior. } 0 \text { aninhamento } \\
\text { permite a formação de redes ad hoc em resposta à } \\
\text { surpresa e aumenta o potencial de inovação local } \\
\text { dentro da governança estável em maior escala. }\end{array}$ \\
\hline & & $\begin{array}{l}\text { - Complementaridade: se um órgão de decisão } \\
\text { deixar de agir ou agir de forma inadequada, outro } \\
\text { órgão pode intervir. }\end{array}$ \\
\hline & & $\begin{array}{l}\text { - Subsidiariedade: tomada de decisão no nível mais } \\
\text { próximo possível do recurso, mas dentro do } \\
\text { contexto de um governo em múltiplas escalas que } \\
\text { promova as condições para a implementação das } \\
\text { decisões de gestão. A subsidiariedade aumenta a } \\
\text { probabilidade de que o conhecimento local seja } \\
\text { usado, as decisões sejam feitas sob medida para } \\
\text { problemas específicos e a inovação possa ocorrer } \\
\text { em nível local, apoiada pela governança em escalas } \\
\text { maiores. }\end{array}$ \\
\hline & Integração & $\begin{array}{l}\text { Integração da gestão de recursos hídricos nos } \\
\text { setores que influenciam a alocação, qualidade e } \\
\text { desenvolvimento da terra, e integração da } \\
\text { regulamentação de recursos fisicamente } \\
\text { conectados, como águas subterrâneas e } \\
\text { superficiais. A integração reduz a possibilidade de } \\
\text { consequências indesejadas. }\end{array}$ \\
\hline & Persistência & $\begin{array}{l}\text { Estabilidade na representação e nos órgãos de } \\
\text { tomada de decisão para promover a legitimidade e } \\
\text { a confiança, reduzindo potencialmente o tempo de } \\
\text { resposta à surpresa. }\end{array}$ \\
\hline \multirow[b]{2}{*}{ Capacidade } & Adaptativa & $\begin{array}{l}\text { Recursos e autoridade legal para responder às } \\
\text { mudanças. Permite que um sistema de governança } \\
\text { se ajuste durante incertezas e mudanças. }\end{array}$ \\
\hline & Participativa & $\begin{array}{l}\text { As pessoas afetadas têm o direito e os recursos } \\
\text { para desempenhar um papel na tomada de } \\
\text { decisões. A capacidade participativa reduz a } \\
\text { probabilidade de marginalização de partes da } \\
\text { sociedade e aumenta a probabilidade de que todos } \\
\text { os aspectos de um sistema sejam considerados na } \\
\text { tomada de decisões. }\end{array}$ \\
\hline
\end{tabular}


Quadro 2 - Continuação...

\begin{tabular}{|c|c|c|}
\hline $\begin{array}{l}\text { Aspectos da } \\
\text { governança } \\
\text { regidos por lei }\end{array}$ & Componente do aspecto & $\begin{array}{l}\text { Diretrizes descritas para avaliação do } \\
\text { componente da estrutura }\end{array}$ \\
\hline \multirow{6}{*}{ Processo } & Legitimidade & $\begin{array}{l}\text { Aceitação da autoridade porque ela é percebida e } \\
\text { exercida de maneira adequada. A legitimidade é } \\
\text { necessária para o apoio público à gestão de } \\
\text { recursos e inclui requisitos para a tomada de } \\
\text { decisões com base científica, deliberação, } \\
\text { responsabilidade, transparência, consistência, } \\
\text { estabilidade e revisão e recurso para aqueles } \\
\text { prejudicados por uma ação governamental. }\end{array}$ \\
\hline & Justiça processual & $\begin{array}{l}\text { Envolve a transparência, o direito de buscar } \\
\text { revisão e engajamento no nível apropriado. A } \\
\text { justiça processual é necessária para identificar } \\
\text { consequências não intencionais, verificar a } \\
\text { corrupção e evitar a aplicação desigual do ônus da } \\
\text { adaptação. }\end{array}$ \\
\hline & Abordagem de resolução de problemas & $\begin{array}{l}\text { Autoridade e recursos para usar a ciência e os } \\
\text { processos colaborativos baseados em interesses. } \\
\text { Permite a possibilidade de soluções benéficas para } \\
\text { todos e contrasta com abordagens políticas e } \\
\text { ideológicas que não estão sujeitas a compromissos }\end{array}$ \\
\hline & Reflexão e aprendizagem & $\begin{array}{l}\text { Recursos para monitoramento e um processo de } \\
\text { feedback e consideração de novas informações. A } \\
\text { oportunidade de reflexão e aprendizagem garante } \\
\text { que a resposta à mudança não seja mecânica e que } \\
\text { a sociedade evolua com a abordagem da gestão. }\end{array}$ \\
\hline & Equilíbrio, estabilidade e flexibilidade & $\begin{array}{l}\text { Prazos de adaptação que consideram tanto a } \\
\text { necessidade de ajuste quanto a necessidade } \\
\text { econômica de estabilidade. O equilíbrio entre } \\
\text { estabilidade e flexibilidade reconhece que, embora } \\
\text { os ajustes devam ocorrer em face da mudança, os } \\
\text { sistemas sociais e, particularmente, os sistemas } \\
\text { econômicos requerem estabilidade; ambos devem } \\
\text { ser levados em consideração. }\end{array}$ \\
\hline & Resolução de conflitos & $\begin{array}{l}\text { Processo para resolução de conflitos e tomada de } \\
\text { decisões finais e vinculativas sobre compensações } \\
\text { em relação a recursos escassos. Pode chegar um } \\
\text { ponto em que o consenso não é possível e, a menos } \\
\text { que um sistema para resolver problemas seja } \\
\text { projetado e acordado de antemão, o conflito é } \\
\text { provável. }\end{array}$ \\
\hline
\end{tabular}

A codificação do corpus e o tratamento dos resultados foram as etapas seguintes. A primeira, consiste em uma transformação do texto que permite ao analista associar parte do texto a um ou mais indicadores (Bardin, 2016). O processo se deu com a leitura do corpus e sempre que fragmentos remetiam ao sentido de algum dos indicadores ele passava a ser codificado como tal. Enquanto a segunda confere aos dados, criados a partir da codificação, interpretações e inferências.

Por se tratar de pesquisa qualitativa com um número considerável de documentos, foi adotado como auxiliador do processo o software Atlas.ti, que permite otimizar o tempo de análise e organizar de forma mais concisa os resultados para que se construam interpretações e inferências mais consistentes do material (Souza Neto et al., 2019). 


\section{RESULTADOS E DISCUSSÕES}

Por meio da análise de conteúdo foi possível perceber que os aspectos intrínsecos à estrutura estão mais presentes nas diretrizes em nível nacional (Figura 3). Em nível local esse aspecto surge uma única vez, quando a Nota Técnica da ANA cita a composição institucional da Coordenação de Marcos Regulatórios e Alocação de Água (COMAR) e suas atribuições, dentre elas a descentralização das atividades de operação e manutenção de reservatórios, canais e adutoras de domínio da União. Essa constatação não é, necessariamente, algo negativo e que prejudique a presença da GA, pois as diretrizes e decisões presentes em outros níveis precisam estar em consonância com as existentes em nível nacional (Agência Nacional de Águas e Saneamento Básico, 2020a) e prerrogativas feitas em dispositivos de nível macro podem ser impactantes em nível micro.

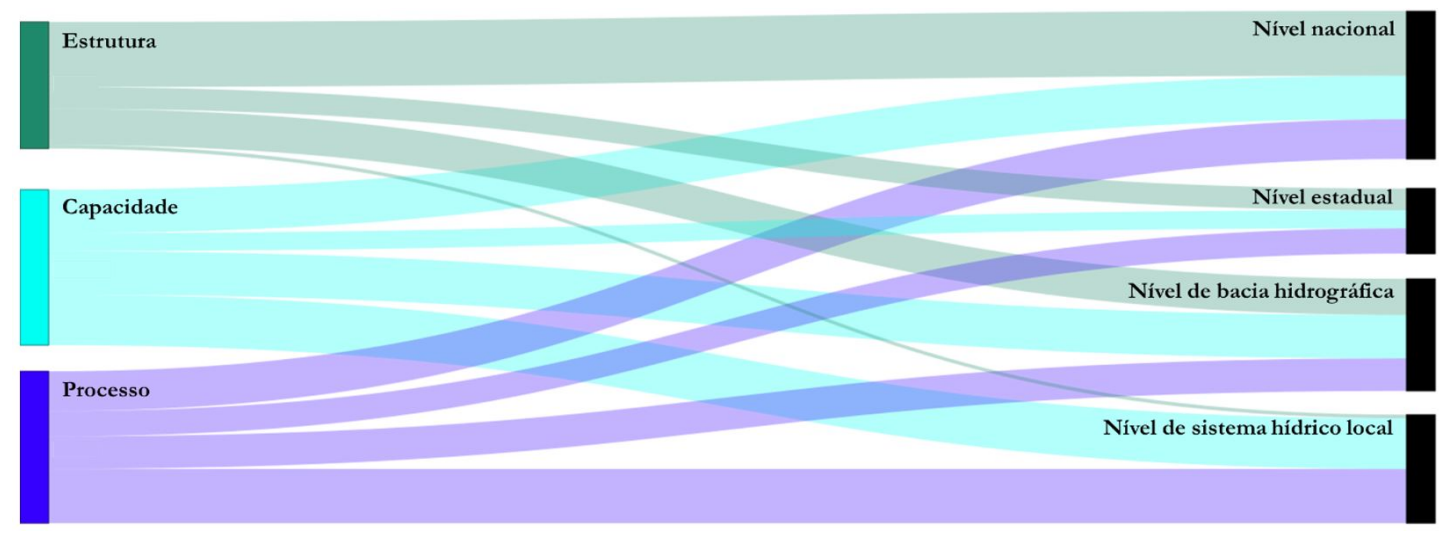

Figura 3 - Diagrama de fluxo para os aspectos da governança regidos por dispositivos jurídicos e normativos nos níveis analisados.

Os indicadores relacionados à estrutura configuram uma preocupação quanto ao aspecto institucional, isto é, aos órgãos que compõem a governança. Nesse sentido a Lei Federal 9.433 define bem o SINGREH em seu texto, inclusive as suas atribuições. 0 mesmo acontece com a lei equivalente no nível estadual para a Paraíba, por meio do Sistema Integrado de Planejamento e Gerenciamento de Recursos Hídricos definido pela Lei Estadual 6.308. Assim como os dispositivos que tratam da composição do comitê da bacia hidrográfica do rio Paraíba. Todos os órgãos contidos nesses níveis, na prática, apresentam importância para a situação analisada no sistema hídrico local.

Nos sistemas hídricos locais as Comissões Gestoras de Açudes (CGA) vinculadas aos comitês de bacia podem fortalecer os indicadores de estrutura, visto que, pela experiência em estados como o Ceará e em bacias como do rio Piranhas-Açu, as CGA são consideradas importantes organismos locais de gestão (Rodrigues, 2014; Oliveira, 2019). Compete às CGA, por exemplo, arbitrar a regra de alocação negociada de água quando não existir consenso entre as partes, acompanhar o cumprimento dos acordos de alocação e propor critérios de uso racional da água (Conselho Estadual de Recursos Hídricos do Ceará, 2007; Comitê da Bacia Hidrográfica do Rio Piancó-Piranhas-Açu, 2014). Na ausência de uma CGA no REP para atuar na governança, quem tem assumido papel de arbitro na alocação negociada de água é a ANA como órgão gestor (Silva \& Ribeiro, 2022), mesmo que a PNRH determine que: "Compete aos Comitês de Bacia Hidrográfica, no âmbito de sua área de atuação, arbitrar, em primeira instância administrativa, os conflitos relacionados aos recursos hídricos” (Brasil, 1997).

Indicadores de capacidade e de processo foram identificados com certa proporcionalidade em todos os níveis a partir dos dispositivos considerados como amostra. Isto sugere uma atenção multinível da condição que os sistemas terão de responder aos cenários de mudanças e a forma que as decisões serão tomadas e implementadas. A presença dessas características associadas à governança das águas sugere uma maior habilidade dos sistemas conseguirem responder às transições no âmbito ecológico (Gunderson, 2000), fortalecer a tomada de decisão com o conhecimento e aceitação dos atores pertencentes ao sistema (Porras et al., 2019; Erdiaw-Kwasie et al., 2020), além de equidade e justiça nas ações acordadas.

A maioria dos indicadores se encontraram presentes no processo de codificação. As redes de conexão entre os indicadores e os níveis (Figura 4) mostram que em âmbito nacional os dispositivos analisados contêm uma maior densidade das características levantadas por Cosens et al. (2017) (Quadro 2). Nesse mesmo nível a policentricidade e a integração dos diferentes órgãos que influenciam 
na governança, são os dois componentes que surgem em mais documentos. Segundo Bettini et al. (2015), características que se assemelham ao que aqui foi definido como policentricidade e integração, corroboram para produzir formas de adaptação por meio da aprendizagem, decisão e ação. Isto ocorre, visto que, ao mesmo tempo que a governança está descentralizada, também demanda uma certa coordenação entre os níveis e setores por meio da integração institucional. Juntas, as duas características auxiliam, por exemplo, na velocidade que o sistema hídrico local leva para elaborar respostas para determinados estresses, desde que os envolvidos em níveis maiores tenham "aprendido" com situações semelhantes e ofereça o suporte devido.

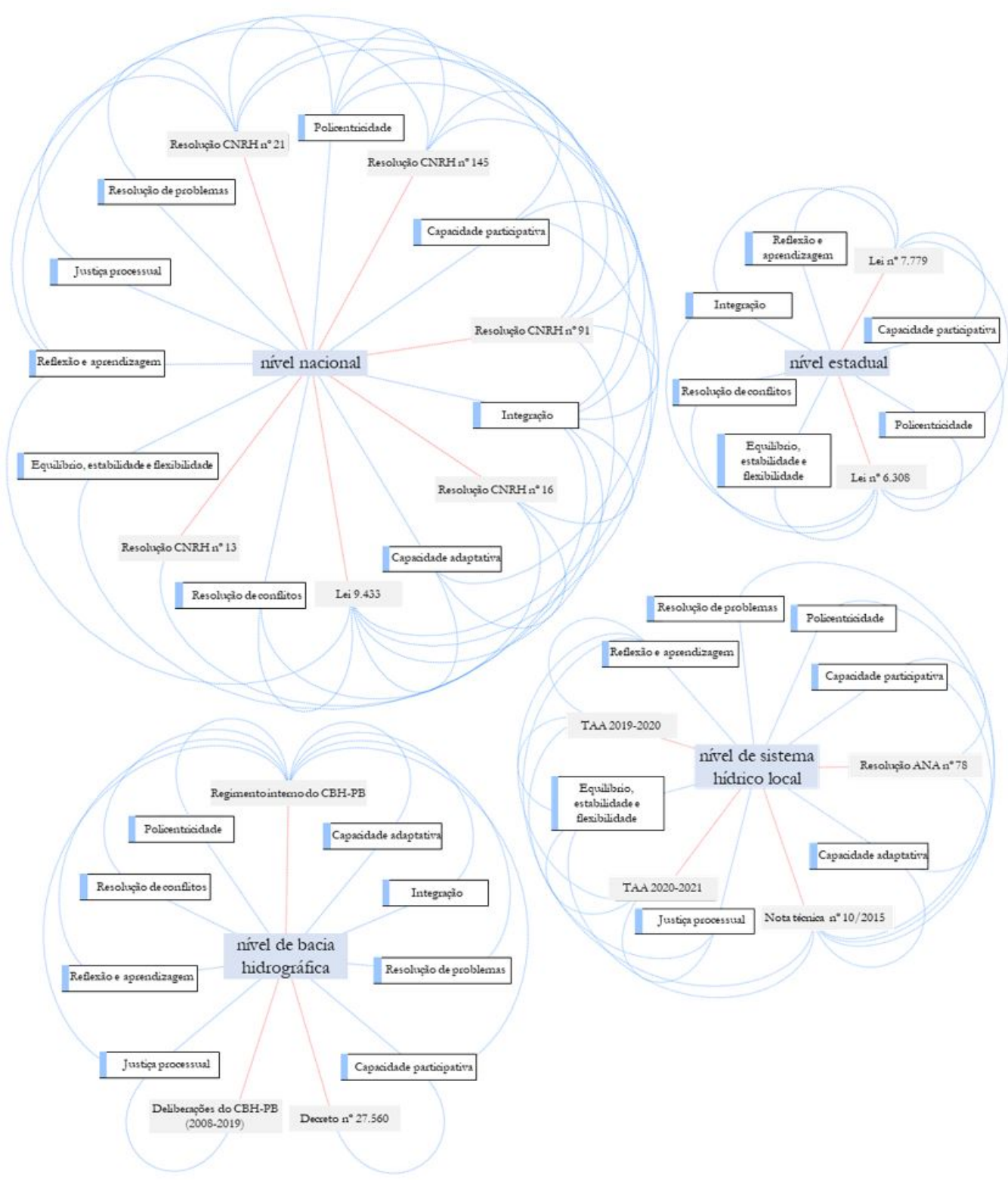

Figura 4 - Redes de conexões para os indicadores da governança adaptativa nos níveis analisados. Links na cor vermelha ligam os níveis aos dispositivos analisados e os links na cor azul ligam os níveis ao indicador e, posteriormente, ao dispositivo em que ele foi identificado.

A policentricidade aqui observada favorece a descentralização na governança das águas, característica marcante da PNRH (Veiga \& Magrini, 2013; Silva et al., 2017; Ribeiro, 2017). Isso se contrapõe a uma estrutura de governança centralizadora, que tende a diminuir o potencial de inovação e, consequentemente, a capacidade adaptativa porque limita a comunicação em uma estrutura predominantemente controlada em um único nível administrativo (Chaffin et al., 2016). 
Ainda nessa discussão, é preciso destacar que a análise de conteúdo se mostrou adequada por ter identificado essa forte presença da policentricidade (também chamado de governança de rede por McGinnis e Ostrom, 2011), pois é uma parte fundamental do modelo de governança das águas presente no Brasil, o que fica bastante evidente ao observar a composição do SINGREH (Figura 5). É importante destacar que o policentrismo e a governança multinível não são sinônimos. Para Pahl-Wostl (2015), a governança multinível pode ser uma característica de sistemas policêntricos e, dessa forma, responsável por distribuir a autoridade para tomada de decisão dentro de uma hierarquia. Complementar a isso, Sandström et al. (2020) esclarecem que todo projeto de governança multinível tem um certo grau de policentrismo. De fato, o que há no Brasil é um sistema de governança com vários níveis para tomada de decisão (policêntrica) e uma hierarquia na qual instituições em um patamar superior podem modificar ou influenciar decisões tomadas em níveis inferiores (multinível). Nesse cenário de governança multinível é preciso fortalece as relações entre as entidades de diferentes níveis, para contribuir com o fluxo de informações, recursos e conhecimentos, assim, favorecendo a adaptação (Hurlbert \& Diaz, 2013).

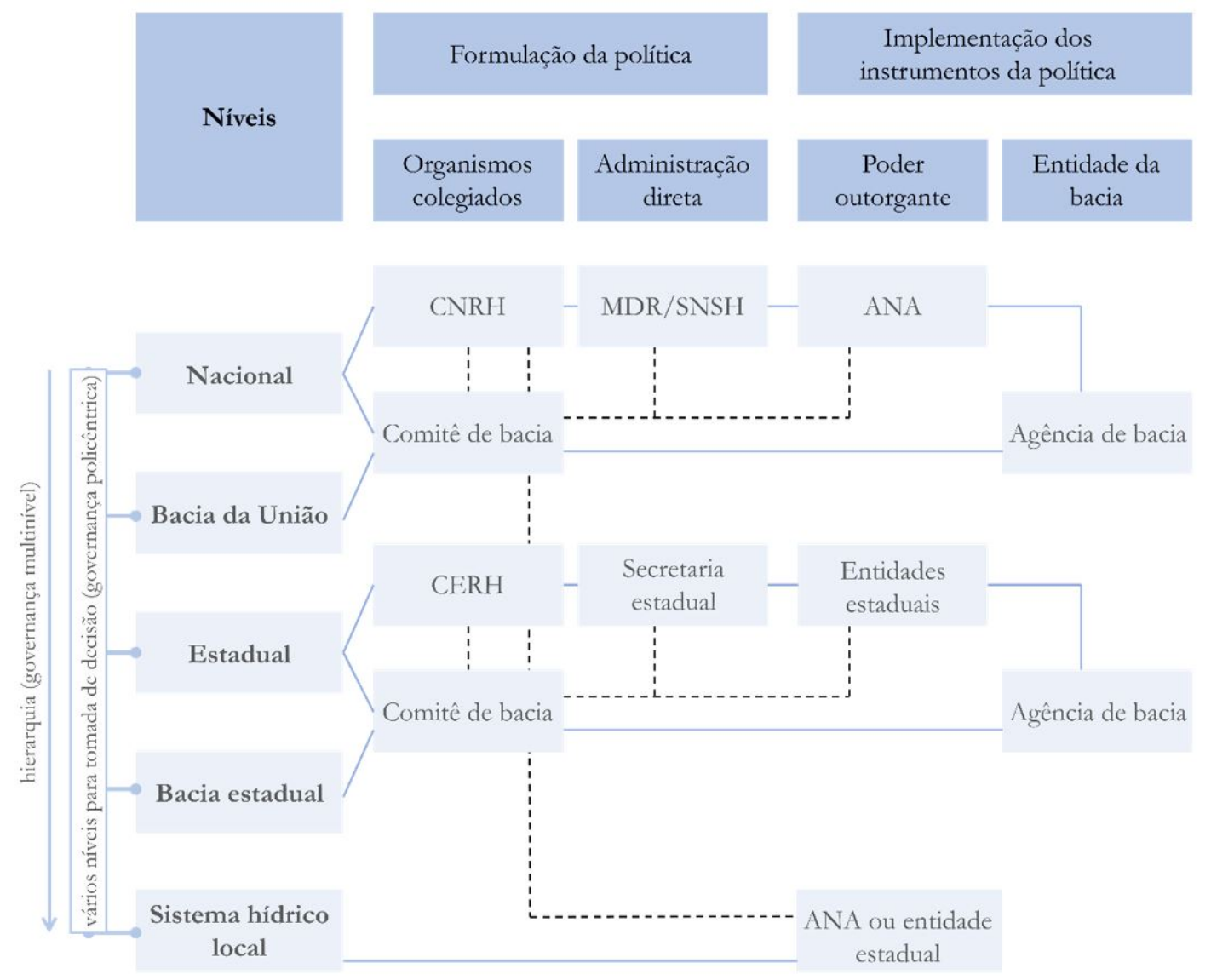

Figura 5 - Matriz e funcionamento do SINGREH adaptado de Agência Nacional de Águas e Saneamento Básico (2020a) e acrescentado o nível de sistema hídrico local.

Os indicadores comuns a todos os níveis são (Figura 4): reflexão e aprendizagem, capacidade participativa e policentricidade. Essas três características juntas permitem, através da GA, que um sistema mantenha a autoridade para a tomada de decisões mais próxima do nível a ser aplicado, assim como aumenta as chances de que todos os pontos de vista sejam levados em consideração na tomada de decisão e que sejam consideradas mudanças menos mecânicas para a adaptação sistêmica (Clarvis et al., 2014; Cosens et al., 2017; Pahl-Wostl, 2020). Na prática para que esses benefícios sejam alcançados faz-se necessário observar, dentre outros aspectos, a representatividade dos atores no processo de tomada de decisão e o conhecimento técnico sobre as questões que envolvem o planejamento.

A persistência e a legitimidade são as duas únicas características que não estão presentes em nenhum dos dispositivos analisados, portanto, em nenhum nível (Figura 4). A primeira porque nos 
órgãos colegiados onde ocorre parte fundamental da tomada de decisão (conselhos e comitês de bacias) as representações e cargos são dadas por meio de mandato, o que não garante a estabilidade na representação para algumas medidas deliberativas, consultivas e até mesmo normativas. A ausência desse tipo de estabilidade pode afetar negativamente o tempo que o sistema levará para responder a pertubações (Cosens et al., 2017). Essa característica também depende de um regime governamental estável. No Brasil, recentemente, a composição de órgãos importantes sofreu alteração refletindo, por exemplo, na diminuição da participação da sociedade civil na representação do Conselho Nacional de Recursos Hídricos (Observatório das Águas, 2019b). Mas esse tipo de estabilidade está voltada para mudanças no grau de representação, como por exemplo, se tem sido constante no comitê de bacia o número de representantes de determinado segmento, respeitanto o estabelecido no dispositivo que regulamenta este aspecto. Aqui o intuito foi relacionar a persistencia à forma como são ocupadas as entidades responsaveis na tomada de decisão acerca dos recursos hídricos, em outras palavras, a estabilidade dos componentes que compõem as entidades.

Na composição institucional dos níveis analisados, a Agência Nacional de Águas e Saneamento Básico (ANA) é o único órgão com quadro de funcionários permanentes sendo formados por meio de concursos e, portanto, se encaixando com o que Cosens et al. (2017) classifica como persistência. Isso permite que o corpo técnico conheça melhor os sistemas que deverão gerir e formem um conhecimento consolidado das problemáticas e vulnerabilidades associadas, auxiliando em respostas mais rápidas e fundamentadas.

A legitimidade é uma característica difícil de ser percebida ou citada em dispositivos jurídicos ou normativos, visto que está associada, dentre outros fatores, à observação do cumprimento de determinadas diretrizes, pois é assim que se legitima uma medida. Isso fez com que não fosse notada menção direta ou indireta nos dispositivos analisados. Em contrapartida, o monitoramento auxilia para a garantia desse indicador ou, mais diretamente, para observância do cumprimento dele. Um exemplo disso está nos dados mensais dos boletins de acompanhamento do COMAR (Figura 6), que mostram que o REP, como sistema hídrico local, tem alcançado as metas estabelecidas nos TAA, respeitando as retiradas acordadas para cada usuário e mantendo o reservatório com o volume próximo ou superior ao planejado. Assim, legitimando a tomada de decisão participativa que vem sendo desenvolvida. No nível de bacias hidrográficas, o Protocolo de Monitoramento do Observatório das Águas (2019a) se mostra uma ferramenta importante para avaliar periodicamente a governança. A análise da legitimidade pode ser aprofundada, pois, para Cosens (2013), a legitimidade que buscouse identificar neste trabalho é o que pode ser classificado como legitimidade baseada em resultados, havendo outras quatro fontes potenciais a serem exploradas: baseada em ordem, sistêmica, deliberativa e processual. Para Cosens et al. (2017), a lei só conseguirá atingir seus objetivos para uma GA se garantir a legitimidade, por isso a importância de haver o monitoramento, como o indicado anteriormente para o nível local.

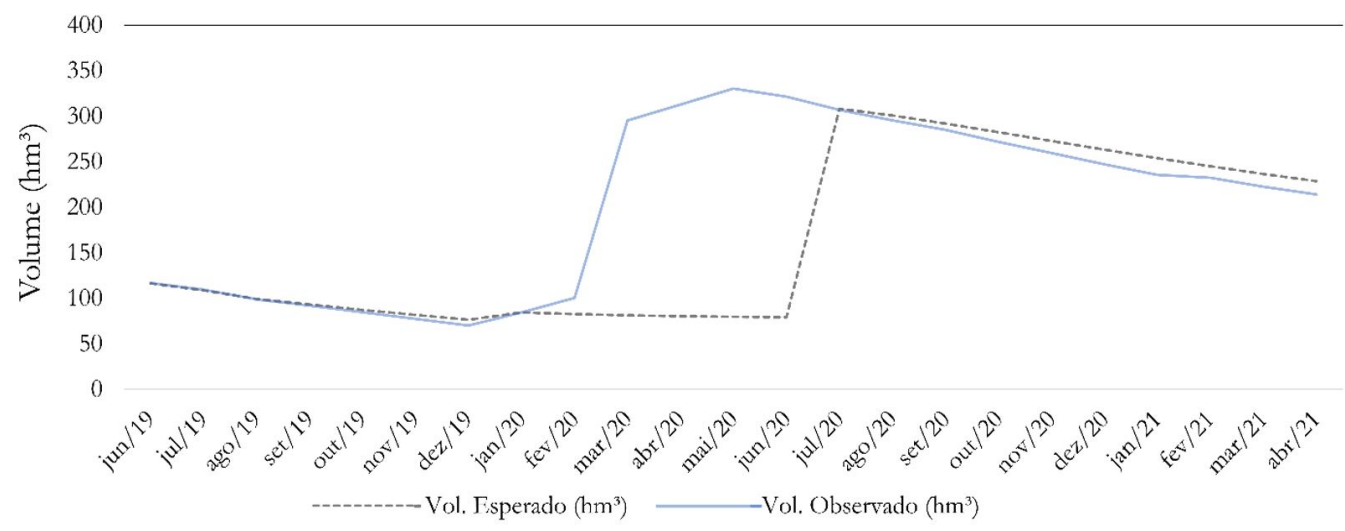

Figura 6 - Dados do COMAR para o monitoramento do volume do Reservatório Epitácio Pessoa.

É importante considerar que a legitimidade baseada em resultados pode se tornar enviesada diante de determinados contextos sociais que não incluam adequadamente algum ator ou grupo de atores envolvido na governança, por exemplo, não levando em consideração os anseios desses atores na tomada de decisão. Desse modo, mesmo que os resultados observados estejam próximos aos esperados, o processo, aparentemente participativo, pode estar sendo coercitivo e os atores, mesmo 
se sentindo prejudicados, estarão condicionados a cumprirem determinado acordo. Portanto, é necessário considerar além da participação, um certo grau de equidade de poder entre os diversos atores, para que assim a legitimade possua um caráter justo e efetivo.

Atentando-se ao ponto focal de análise, que foi o sistema hídrico local composto pelo REP, os resultados alcançados demonstram uma forte presença de elementos da GA nos dispositivos e acordos que orientam a governança neste nível. Essa constatação se deve sobretudo ao processo de alocação negociada de água que vem sendo desenvolvido. Este é considerado um processo de regulação responsiva que modifica a abordagem puramente fundamentada em comando e controle e proporciona uma atuação mais democrática e participativa (Spolidorio, 2017). A participação nas reuniões tem sido substancial, incluindo atores dos diversos campos de interesses na exploração do reservatório (abastecimento, irrigação e aquicultura) (Agência Nacional de Águas e Saneamento Básico, 2021). A Figura 7 apresenta algumas caracteristicas desse modelo de alocação que tendem a fortalecer alguns aspectos da GA.

\begin{tabular}{|c|}
\hline Policentricidade \\
\hline $\begin{array}{l}\text { A atuação da Coordenação de Marcos Regulatórios e } \\
\text { Alocação de Água (COMAR) faz com que a tomada de } \\
\text { decisão ocorra no nível em que o recurso está e deve ser } \\
\text { gerido. Fazem parte dos acordos, representantes de } \\
\text { órgãos de outros niveis, como do comitê de bacia. O } \\
\text { fato de existir uma Comissão de Monitoramento que } \\
\text { inclui uma ampla gama dos atores envolvidos na } \\
\text { governança é outro indicativo para a descentralização } \\
\text { das medidas. }\end{array}$ \\
\hline Capacidade adaptativa \\
\hline $\begin{array}{l}\text { Leva em consideração para o planejamento e gestão, os } \\
\text { Estados Hidrológicos que são definidos por meio de } \\
\text { curvas-guia. Isso permite que os volumes retirados } \\
\text { possam ser ajustados de acordo com o estado em que o } \\
\text { reservatório se encontra. Por isso, a metodologia } \\
\text { propõe que as discussões e definição dos Estados } \\
\text { Hidrológicos sejam feitas periodicamente e sempre após } \\
\text { o período úmido, para levar em consideração a situação } \\
\text { do sistema no momento permitindo que haja adaptação } \\
\text { aos períodos críticos. }\end{array}$ \\
\hline Justiça processual \\
\hline $\begin{array}{l}\text { A comissão de acompanhamento da alocação de água } \\
\text { pode propor à COMAR ajustes nos valores acordados a } \\
\text { partir do final do período de estiagem e podem solicitar } \\
\text { defluência para os usuários à jusante, caso haja real } \\
\text { necessidade. Assim evitando ou minimizando o ônus de } \\
\text { possíveis medidas adaptativas. }\end{array}$ \\
\hline Reflexão e aprendizagem \\
\hline $\begin{array}{l}\text { Os boletins de acompanhamento disponibilizados } \\
\text { mensalmente são importantes ferramentas para a } \\
\text { reflexão sobre os acordos e constante aprendizagem. } \\
\text { Neles há informações sobre o monitoramento do } \\
\text { volume acumulado do reservatório e dos usos, cabendo } \\
\text { à Comissão de Acompanhamento cobrar pelo } \\
\text { cumprimento dos compromissos, caso não estejam } \\
\text { sendo realizados. }\end{array}$ \\
\hline
\end{tabular}

Figura 7 - Algumas características do processo de alocação negociada de água associadas a aspectos que favorecem a governança adaptativa.

A presença ou não dos indicadores analisados não qualifica por si só a governança como adaptativa, mas apresenta indícios de que a dimensão legal e institucional da governança tem em sua composição elementos que tendem a favorecer os sistemas hídricos na assimilação de incertezas e pertubações. Sendo assim, as caracteristicas levantadas por Cosens et al. (2017) e investigadas neste 
trabalho em vários níveis apontam para uma condição positiva, mas somente a implementação desses dispositivos pode medir a efetividade das diretrizes.

Por mais que os dispositivos se atentem aos vários aspectos necessários à GA, é necessário considerar a dificuldade de implementação, pois isso perpassa aspectos problemáticos relacionados à governabilidade, heterogeniedade em um país com dimensões continentais e desinformação social. Souza Filho (2011) ao explorar desafios para implementação da PNRH, sugere componentes de ação para que seja possível superá-los, dentre eles, o fortalecimento institucional e a participação (seja por meio dos comitês de bacias ou comissões gestoras de açudes). Portanto, estas também são medidas que podem facilitar a implementação de uma GA em sistemas hídricos brasileiros. Entende-se que deve o comitê de bacia ser, também, fiscal da boa implementação do plano da bacia verificando se ações e programas aprovados estão sendo obedecidos. Sousa Júnior et al. (2016) consideram que na prática a participação na governança brasileira da água é prejudicada porque os comitês de bacia, importantes arenas para discussões, ainda são desafiados negativamente por questões políticas, técnicas e operacionais, como a desigual distribuição de autoridade entre as partes interessadas no recurso. De acordo com Lemos et al. (2020) poucos grupos controlam a produção do conhecimento e a tomada de decisão em momentos de crises de sistemas hídricos brasileiros, o que dificulta a capacidade adaptativa.

A quantidade de dispositivos jurídicos e normativos que influencia direta ou indiretamente a governança das águas no Brasil é bastante ampla e, por isso, a análise feita não classifica como findada a investigação do caráter adaptativo. No entanto, para a governança praticada no REP, o ordenamento jurídico e normativo apresenta-se com características que podem ajudar o corpo hídrico a lidar com as rápidas mudanças socioambientais.

\section{CONCLUSÕES}

Na Lei 9.433/97, da Política Nacional de Recursos Hídricos, encontra-se disposto, em um dos seus fundamentos, que "a gestão dos recursos hídricos deve ser descentralizada e contar com a participação do Poder Público, dos usuários e das comunidades”. A integração entre setores usuários assim como a articulação entre a gestão de recursos hídricos, a gestão ambiental e o uso do solo também estão previstas na PNRH. Nesta pesquisa verifica-se que esses modernos aspectos (descentralização, participação, integração, articulação), essenciais para o alcance de uma Governança Adaptativa, são contemplados nos dispositivos analisados. Isso pode ser verificado nos níveis nacional (resoluções do $\mathrm{CNRH}$ ); estaduais (leis); de bacia hidrográfica (deliberações de comitê) e sistema hídrico local (termos de alocaçao de água).

Considerar as discussões no nível de sistema hídrico local (contextualizando-as em nível macro) é muito adequado para o Brasil. Isso tem muita relevância em casos em que grande parte da demanda de água é satisfeita com os reservatórios de regularização de vazão, como no semiárido. A análise mostrou que o planejamento realizado para estes sistemas pode fortalecer muito a presença da Governança Adaptativa, essencialmente e muito recentemente, devido ao processo de alocação negociada de água. A alocação de água que vem sendo desenvolvida no REP é uma iniciativa da ANA em reservatórios com águas de domínio da União, mas é um direcionamento para que órgãos gestores estaduais utilizem a metodologia em reservatórios com águas de domínio estadual.

A pesquisa foi realizada em um Estado com política de recursos hídricos, em uma bacia com comitê e em um reservatório de importância para a população de diversos municípios paraibanos, o qual passou a ser melhor observado após a crise vivenciada - o que tem desencandeado recente interesse em ter sua governança aperfeiçoada. 0 panorama encontrado pode ser bem distinto para outros estados, bacias e reservatórios. Por isso, sugere-se que esta investigação seja realizada para outros sistemas, proporcionando, inclusive, a comparação e diretrizes para melhorias.

Há uma lacuna entre a concepção da política hídrica no Brasil (e a respectiva regulamentação) e os resultados alcançados quando da implementação. Por mais que nesta pesquisa tenham surgido indícios que apontam para uma governança brasileira de águas de caráter adaptativo, faz-se necessário examinar sua implementação e resolver as barreiras que a limita. Como nenhum sistema se encontra isolado, a presença de indicadores em um nível mais macro deve ter influência direta na situação local. Isso é essencial em casos de governança de águas onde as instituições estão conectadas em um sistema de gerenciamento - como no caso brasileiro. 


\section{AGRADECIMENTOS}

0 primeiro autor agradece a bolsa de estudo concedida pela Coordenação de Aperfeiçoamento de Pessoal de Nível Superior (CAPES). Todos os autores agradecem ao CNPq pelo financiamento do Projeto "Governança de água: análise e avaliação em contexto de múltiplas escalas e dupla dominialidade" (processo 421877/2018-9) do qual esta pesquisa faz parte.

\section{REFERÊNCIAS}

Agência Nacional de Águas e Saneamento Básico - ANA. (2017, 1 de novembro). Resolução no 1.934, de 30 de outubro de 2017. Aprova o Regimento Interno e o Quadro Demonstrativo de Cargos em Comissão da Agência Nacional de Águas - ANA. Diário Oficial [da] República Federativa do Brasil, Brasília. Recuperado em 15 de março de 2021, de https://arquivos.ana.gov.br/resolucoes/2017/1934-2017.pdf

Agência Nacional de Águas e Saneamento Básico - ANA. (2020a). Direito de águas à luz da governança. Brasília: ANA.

Agência Nacional de Águas e Saneamento Básico - ANA. (2020b). Termo de alocação de água 2020/2021: sistema hídrico Epitácio Pessoa (PB). Recuperado em 20 de maio de 2021, de https://www.gov.br/ana/pt-br/todosos-documentos-do-portal/documentos-sre/resolucoes-e-normativos/regras-especiais-de-uso-daagua/alocacao-de-agua/pb-1/termo-de-alocacao-de-agua-epitacio-pessoa-2020-2021.pdf

Agência Nacional de Águas e Saneamento Básico - ANA. (2021). Alocação de água. Recuperado em 11 de maio de 2021, de https://www.ana.gov.br/regulacao/resolucoes-e-normativos/regras-especiais-de-uso-daagua/alocacao-de-agua-inicial

Armitage, D., Loë, R., \& Plummer, R. (2012). Environmental governance and its implications for conservation practice. Conservation Letters, 5(4), 245-255.

Assis, W. D., Ribeiro, M. M. R., \& Silva, S. R. (2020). Multi-level governance application to a shared river basin. Revista Brasileira de Recursos Hídricos, 25, 1-16.

Bardin, L. (2016). Análise de conteúdo. São Paulo: Edições 70.

Bettini, Y., Brown, R. R., \& Haan, F. J. (2015). Exploring institutional adaptive capacity in practice: examining water governance adaptation in australia. Ecology and Society, 20(1), 1-21.

Bezerra, A. P. (2019). Governança de água para distintos níveis de planejamento no semiárido da Paraíba: análise para o período 2012-2018 (Dissertação de mestrado). Universidade Federal de Campina Grande, Campina Grande.

Brasil. (1988). Constituição da República Federativa do Brasil. Brasília: Centro Gráfico.

Brasil. (1997, 8 de janeiro). Lei no 9.433, de 8 de janeiro de 1997. Institui a Política Nacional de Recursos Hídricos. Diário Oficial da União, Brasília. Recuperado em 18 de novembro de 2020, de http://www.planalto.gov.br/ccivil_03/Leis/L9433.htm

Cash, D. W., Adger, W. N., Berkes, F., Garden, P., Lebel, L., Olsson, P., Pritchard, L., \& Young, O. (2006). Scale and Cross-Scale Dynamics: governance and information in a multilevel world. Ecology and Society, 11(2), 1-12.

Chaffin, B. C., \& Gunderson, L. H. (2016). Emergence, institutionalization and renewal: rhythms of adaptive governance in complex social-ecological systems. Journal of Environmental Management, 165, 81-87.

Chaffin, B. C., Garmestani, A. S., Gosnell, H., \& Craig, R. K. (2016). Institutional networks and adaptive water governance in the Klamath River Basin, USA. Environmental Science \& Policy, 57, 112-121.

Chaffin, B. C., Gosnell, H., \& Cosens, B. A. (2014). A decade of adaptive governance scholarship: synthesis and future directions. Ecology and Society, 19(3), 1-13.

Clarvis, M. H., Allan, A., \& Hannah, D. M. (2014). Water, resilience and the law: from general concepts and governance design principles to actionable mechanisms. Environmental Science \& Policy, 43, 98-110.

Comitê da Bacia Hidrográfica do Rio Piancó-Piranhas-Açu - CBH-PPA. (2014). Deliberação nº 18/2014. Recuperado em 18 de junho de 2021, de http://cbhpiancopiranhasacu.org.br/Docs/Deli/Deliberacao_n_018-2014.pdf

Conselho Estadual de Recursos Hídricos do Ceará - CONERH. (2007, 20 de novembro). Resolução no 02, de 20 de novembro de 2007. Dispõe sobre as comissões gestoras de sistemas hídricos. Diário Oficial do Estado, Fortaleza. Recuperado em 16 de junho de 2021, de http://www.cbhrmf.com.br/resolucoes/resolucaoconerh-no-02-20-de-novembro-de-2007/

Cosens, B. (2013). Legitimacy, Adaptation, and Resilience in Ecosystem Management. Ecology and Society, 18(1), 1-9. 
Cosens, B. (2015). Application of the adaptive water governance project to the management of the Lake Eyre Basin and its connections to the Great Artesian Basin. Adelaide: Flinders University and Goyder Institute for Water Research.

Cosens, B. A., Craig, R. K., Hirsch, S. L., Arnold, C. A., Benson, M. H., Decaro, D. A., Garmestani, A. S., Gosnell, H., Ruhl, J. B., \& Schlager, E. (2017). The role of law in adaptive governance. Ecology and Society, 22(1), 1-13.

Cosens, B., \& Gunderson, L. (2021). Adaptative governance in north american water systems: a legal perspective on resilience and reconciliation. In J. Baird \& R. Plummer (Eds.), Water resilience: management and governance in times of change (pp. 171-192). Cham: Springer Nature.

Cosens, B., Gunderson, L., \& Chaffin, B. (2014a). The adaptive water governance project: assessing law, resilience and governance in regional socio-ecological water systems facing a changing climate. 51. Idaho Law Review, 1,1-27.

Cosens, B., Gunderson, L., Allen, C., \& Benson, M. (2014b). Identifying legal, ecological and governance obstacles, and opportunities for adapting to climate change. Sustainability, 6(4), 2338-2356.

Craig, R. K., Garmestani, A. S., Allen, C. R., Arnold, C. A., Birgé, H., Decaro, D. A., Fremier, A. K., Gosnell, H., \& Schlager, E. (2017). Balancing stability and flexibility in adaptive governance: an analysis of tools available in u.s. environmental law. Ecology and Society, 22(2), 1-15.

Daniell, K. A., \& Barreteau, O. (2014). O. Water governance across competing scales: coupling land and water management. Journal of Hydrology, 519, 2367-2380.

DeCaro, D. A., Chaffin, B. C., Schlager, E., Garmestani, A. S., \& Ruhl, J. B. (2017). Legal and institutional foundations of adaptive environmental governance. Ecology and Society, 22(1), 1-20.

Erdiaw-Kwasie, M. O., Abunyewah, M., Edusei, J., \& Alimo, E. B. (2020). Citizen participation dilemmas in water governance: an empirical case of kumasi, Ghana. World Development Perspectives, 20, 100242.

Franco, M. L. P. B. (2008). Análise de conteúdo. Brasília: Líber Livro.

Granziera, M. L. M. (2003). Direito de águas: disciplina jurídica das águas doces. São Paulo: Atlas.

Gunderson, L. H. (2000). Ecological resilience: in theory and application. Annual Review of Ecology and Systematics, 31(1), 425-439.

Hulbert, M. A., \& Diaz, H. (2013). Water governance in Chile and Canada: a comparison of adaptive characteristics. Ecology and Society, 18(4), 1-15.

Hurlbert, M., \& Gupta, J. (2016). Adaptive governance, uncertainty, and risk: policy framing and responses to climate change, drought, and flood. Risk Analysis, 36(2), 339-356.

Instituto Brasileiro de Geografia e Estatística - IBGE. (2018). Cidades. Recuperado em 13 de junho de 2020, de https://cidades.ibge.gov.br/

Knieper, C., \& Pahl-Wostl, C. (2016). A comparative analysis of water governance, water management, and environmental performance in river basins. Water Resources Management, 30(7), 2161-2177.

Kumar, P. (2015). Hydrocomplexity: addressing water security and emergent environmental risks. Water Resources Research, 51(7), 5827-5838.

Lemos, M. C., Puga, B. P., Formiga-Johnsson, R. M., \& Seigerman, C. K. (2020). Building on adaptive capacity to extreme events in Brazil: water reform, participation, and climate information across four river basins. Regional Environmental Change, 20(2), 1-13.

McGinnis, M. D., \& Ostrom, E. (2011). Reflections on Vincent Ostrom, Public Administration, and Polycentricity. Public Administration Review, 72(1), 15-25.

McGinnis, M. D., \& Ostrom, E. (2014). Social-ecological system framework: initial changes and continuing challenges. Ecology and Society, 19(2), 1-12.

Novellie, P., Biggs, H., \& Roux, D. (2016). National laws and policies can enable or confound adaptive governance: examples from south african national parks. Environmental Science \& Policy, 66, 40-46.

Observatório das Águas - OGA. (2019a). Protocolo de monitoramento de governança das águas. OGA.

Observatório das Águas - OGA. (2019b). Governança da água está enfraquecida por decreto. Recuperado em 30 de novembro de 2020, de https://www.wwf.org.br/?72802/Governanca-da-agua-esta-enfraquecida-pordecreto 
Oliveira, P. A. (2019). Mensurando a governança da água em bacias hidrográficas compartilhadas no Brasil: proposta metodológica e aplicação à bacia do rio Piranhas-Açu (Tese de doutorado). Universidade Federal de Campina Grande, Campina Grande.

Organization for Economic Co-operation and Development - OECD. (2015). OECD principles on water governance. Paris: OECD Water Governance Programme.

Ostrom, E. (2007). A diagnostic approach for going beyond panaceas. Proceedings of the National Academy of Sciences of the United States of America, 104(39), 15181-15187.

Pahl-Wostl, C. (2015). Water governance: concepts, methods, and practice. Switzerland: Springer.

Pahl-Wostl, C. (2017). An evolutionary perspective on water governance: from understanding to transformation. Water Resources Management, 31(10), 2917-2932.

Pahl-Wostl, C. (2019). The role of governance modes and meta-governance in the transformation towards sustainable water governance. Environmental Science \& Policy, 91, 6-16.

Pahl-Wostl, C. (2020). Adaptive and sustainable water management: from improved conceptual foundations to transformative change. International Journal of Water Resources Development, 36(2-3), 397-415.

Pahl-Wostl, C., Lebel, L., Knieper, C., \& Nikitina, E. (2012). From applying panaceas to mastering complexity: toward adaptive water governance in river basins. Environmental Science \& Policy, 23, 24-34.

Pedrosa, V. A. (2020). Construindo pactos pelo uso da água. Brasília: ANA, UNESCO.

Plummer, R., \& Baird, J. (2021). The emergence of water resilience: an introduction. In J. Baird \& R. Plummer (Eds.), Water resilience: management and governance in times of change (pp. 3-22). Cham: Springer Nature.

Porras, G. L., Stringer, L. C., \& Quinn, C. H. (2019). Corruption and conflicts as barriers to adaptive governance: water governance in dryland systems in the Rio del Carmen watershed. The Science of the Total Environment, 660, 519-530.

Rêgo, J. C., Galvão, C. O., Vieira, Z. M. C. L., Albuquerque, J. P. T., Ribeiro, M. M. R., \& Souza, J. A. (2017). A gestão de recursos hídricos e a transposição de águas do Rio São Francisco para o Açude Epitácio Pessoa - Boqueirão. In Anais do XXII Simpósio Brasileiro de Recursos Hídricos (pp. 1-8). Florianópolis: Associação Brasileira de Recursos Hídricos.

Ribeiro, M. A. F. M., Vieira, Z. M. C. L., \& Ribeiro, M. M. R. (2012). Participatory and decentralized water resources management: challenges and perspectives for the north Paraíba river basin committee - Brazil. Water Science and Technology, 66(9), 2007-2013.

Ribeiro, M. M. R. (2017). A few comments on the brazilian water resource policy. New Water Policy \& Practice Journal, 22-32.

Ribeiro, N. B., \& Johnsson, R. M. F. (2018). Discussions on water governance: patterns and common paths. Ambiente \& Sociedade, 21, 1-22.

Rodrigues, C. R. (2014). Indicadores para avaliação de comissões gestoras de sistemas hídricos e sua aplicação na análise das bacias da região metropolitana de Fortaleza (Dissertação de mestrado). Universidade Federal do Ceará, Fortaleza.

Ruhl, J. B. (2011). General design principles for resilience and adaptive capacity in legal systems: applications to climate change adaptation law. North Carolina Law Review, 89, 1373-1401.

Sandström, A., Söderberg, C., \& Nilsson, J. (2020). Adaptive capacity in different multi-level governance models: a comparative analysis of swedish water and large carnivore management. Journal of Environmental Management, 270, 110890.

Scholz, J., \& Stiftel, B. (2005). Adaptive governance and water conflict: new institutions for collaborative planning. New York: Routledge.

Shivakumar, S. (2005). The Constitution of development: crafting capabilities for self-governance. New York: Palgrave Macmillan.

Silva, A. C. S., Galvão, C. O., Ribeiro, M. M. R., \& Silva, A. T. (2017). Adaptation to climate change: institutional analysis. In E. Kolokytha, S. Oishi \& R. Teegavarapu (Eds.), Sustainable water resources planning and management under climate change (pp. 261-280). Cingapura: Springer.

Silva, J. F. C. B. C., Silva, R. M., Santos, C. A. G., Silva, A. M., \& Vianna, P. C. G. (2021). Analysis of the response of the Epitácio Pessoa reservoir (Brazilian semiarid region) to potential future drought, water transfer and LULC scenarios. Natural Hazards, 107, 1-25. 
Silva, M. B. M., \& Ribeiro, M. M. R. (2022). Alocação e governança da água como mecanismos de resolução de conflitos. Engenharia Sanitária e Ambiental. No prelo.

Sivapalan, M., Savenije, H. H. G., \& Blöschl, G. (2012). Socio-hydrology: a new science of people and water. Hydrological Processes, 26(8), 1270-1276.

Sousa Júnior, W., Baldwin, C., Camkin, J., Fidelman, P., Silva, O., Neto, S., \& Smith, T. (2016). Water: drought, crisis and governance in Australia and Brazil. Water, 8(11), 493-514. http://dx.doi.org/10.3390/w8110493

Souza Filho, F. A. (2011). A política nacional de recursos hídricos: desafios para sua implantação no semiárido brasileiro. In S. S. Medeiros, H. R. Cheyi, C. O. Galvão \& V. P. S. Paz (Eds.), Recursos hídricos em regiões áridas e semiáridas (pp. 1-25). Campina Grande: Instituto Nacional do Semiárido.

Souza Neto, R. A., Dias, G. F., Silva, R. R., \& Ramos, A. S. M. (2019). Efeitos dos softwares de análise de dados qualitativos na qualidade de pesquisas. Revista de Administração Contemporânea, 23(3), 373-394.

Spolidorio, P. C. M. (2017). A alocação negociada de água como estratégia de regulação responsiva. Journal of Law and Regulation, 3(1), 183-198.

Neto, S., Camkin, J., Fenemor, A., Tan, P.-L., Baptista, J. M., Ribeiro, M., Schulze, R., Stuart-Hill, S., Spray, C., \& Elfithri, R. (2017). OECD principles on water governance in practice: an assessment of existing frameworks in europe, asia-pacific, africa and south america. Water International, 43(1), 60-89.

Veiga, L. B. E., \& Magrini, A. (2013). The Brazilian water resources management policy: fifteen years of success and challenges. Water Resources Management, 27(7), 2287-2302.

\section{Contribuições dos autores:}

Maycon Breno Macena da Silva: concepção do trabalho, escrita geral, levantamento bibliográfico, coleta de dados, análise e discussão dos resultados.

Márcia Maria Rios Ribeiro: revisão geral do artigo, orientação, análise e discussão dos resultados. 